
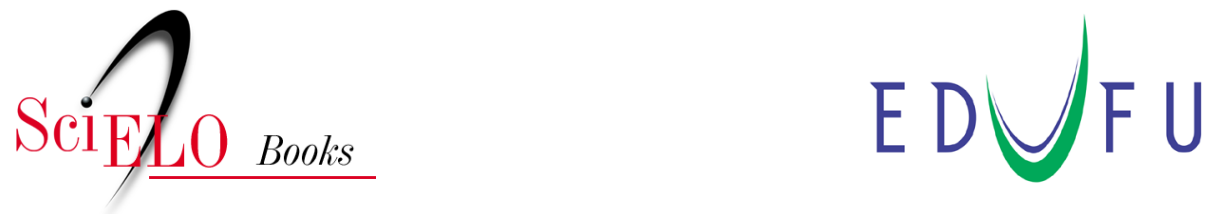

\title{
Escrevendo na e para academia um estudo sobre a incorporação do discurso acadêmico no gênero relato de experiência
}

Roberta Andrade Meneses

Williany Miranda da Silva

\section{SciELO Books / SciELO Livros / SciELO Libros}

MENESES, R.A., and SILVA, W.M. Escrevendo na e para academia: um estudo sobre a incorporação do discurso acadêmico no gênero relato de experiência. In: AGUSTINI, C., and ERNESTO, B., eds. Incursões na escrita acadêmico-universitária: letramento, discurso, enunciação [online]. Uberlândia: EDUFU, 2017, pp. 221-237. ISBN: 978-6586084-26-9. https://doi.org/10.7476/9786586084269.0013.

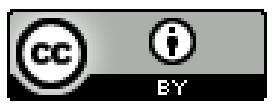

All the contents of this work, except where otherwise noted, is licensed under a Creative Commons Attribution 4.0 International license.

Todo o conteúdo deste trabalho, exceto quando houver ressalva, é publicado sob a licença Creative Commons Atribição 4.0. 


\section{Escrevendo na e para academia: um estudo sobre a incorporação do discurso acadêmico no gênero relato de experiência}

Roberta Andrade Meneses

Williany Miranda da Silva

Nas últimas décadas, tem-se notabilizado um crescente interesse no tocante aos estudos enfocando a produção escrita de textos acadêmicos, tais quais: projetos de pesquisa, artigos científicos, resenhas acadêmicas, Abstracts, dentre outros (Motta-Roth; Hendges, 2010). Essas produções materializam um conjunto de normas tácitas ou mesmo explícitas impostas pela comunidade acadêmico-científica, caracterizada por assumir uma ordem do discurso particular, muitas vezes estranha aos seus membros neófitos.

Tendo em vista tal realidade, este trabalho tem por objetivo depreender que estratégias os sujeitos graduandos, inseridos em contexto de produção de texto especializado, mobilizam para integrarem-se à comunidade discursiva acadêmica. Conforme Swales (1990), a noção de comunidade discursiva diz respeito à ideia de um grupo de indivíduos partilhando objetivos públicos comuns (há também os interesses particulares - implícitos ou explícitos). Esses indivíduos, ao ligarem-se por interesses, práticas e atividades em comum, utilizam-se de convenções discursivas específicas, atestadoras da identidade do grupo, de modo que seus discursos revelam os conhecimentos partilhados (Swales, 1990). 
Orientada pelo paradigma interpretativista, de viés documental, nossa pesquisa compreendeu a análise de um corpus constituído por vinte exemplares do gênero relato de experiência, produzidos no âmbito da disciplina Estudos de Oralidade e Escrita, por graduandos recémingressos no curso de Letras de uma universidade pública federal. A partir disso, promovemos um recorte no corpus, elegendo a unidade retórica referente à Apresentação da experiência - introdução, de dois dos relatos coletados, um que atende ao esperado para esse gênero, outro que não, sendo ambos os sujeitos produtores pertencentes ao $2^{\circ}$ período do curso de Letras.

Desse modo, foi possível depreender que os produtores utilizaram-se de diferentes estratégias para a produção do texto especializado, evidenciando, consequentemente, ocuparem diferentes estágios de desenvolvimento de escrita acadêmica, bem como de apropriação do discurso acadêmico-científico.

Com vistas a atender ao que nos propomos, o plano organizacional deste trabalho apresenta, além desta introdução, as seguintes seções: 1 - Letramento acadêmico: uma linguagem social específica, 2 Desenvolvimento de escrita: a aquisição de conhecimentos e 3 - Escrevendo na e para a academia o gênero relato de experiência, referentes à apresentação e discussão dos subsídios teóricos utilizados. Na seção 4, Unidade 1 - Apresentação da experiência, damos início à análise dos dados; seguida das conclusões, e, por fim, das referências utilizadas no trabalho.

\section{Letramento acadêmico: uma linguagem social específica}

A compreensão do letramento como uma prática social situada, a qual só se notabiliza a partir dos significados políticos e ideológicos que assume (Street, 2010), marca um novo plano conceitual no modo como a escrita é concebida, trata-se dos Novos Estudos do Letramento (Street, 1984; Barton, 1994; Barton; Hamilton, 2000; Gee, 1996, 2001).

Conforme essa perspectiva, a escrita passa a ser tomada considerando-se seus usos sociais, que se orientam segundo práticas culturais discursivas, dependentes do contexto e seus arranjos sociais. Nesse sentido, o letramento é um fenômeno situado, adquirindo significados a partir das funções que assume em dada formação social. 
Escrevendo na e para academia: um estudo sobre a incorporação do discurso...

Em se tratando da esfera acadêmica, temos a noção de letramento acadêmico, que pode ser entendida, sob uma perspectiva geral, como a capacidade de ser fluente em modos de pensar, ser, fazer, ler e escrever nessa esfera de atividade humana (cf. Fischer, 2008).

Tal fluência envolve a mobilização de conhecimentos de ordem formal e discursiva para a produção de gêneros típicos. Em outras palavras, escrever academicamente requer um conhecimento metacognitivo específico, geralmente incomum aos não membros da comunidade discursiva acadêmica. Assim, sujeitos candidatos a inserirem-se nessa comunidade encontram-se em processo de desenvolvimento de escrita, porém, não qualquer escrita, mas sim uma escrita particular, atestadora da filiação à ordem do discurso acadêmico científico, materializada em gêneros típicos do texto especializado.

\section{Desenvolvimento de escrita:}

a aquisição de conhecimentos

Embora a noção de desenvolvimento de escrita costume se ligar à aquisição do código por sujeitos em fase inicial de escolarização (Ferreira, 2014), entendemos, conforme Klemp (2004), que o letramento acadêmico é um processo no qual há desenvolvimento contínuo quanto aos conhecimentos que orientam a interação mediada pelos textos especializados desse domínio. Portanto, ser academicamente letrado atesta a condição daquele que adquiriu estratégias eficazes para compreender e usar as linguagens demandadas pelos textos especializados que circulam na academia.

Coadunando-se a essa ideia, Ferreira (2014), ao tomar por base Beaufort (1998 apud Swales, 2009) e Tardy (2009), propõe-nos cinco conhecimentos para a produção do texto especializado em domínio acadêmico: os conhecimentos do gênero, da norma linguística padrão, do processo de escrita, do assunto e, por fim, da comunidade discursiva acadêmica, que engloba todos os conhecimentos anteriores.

Desse modo, o sujeito graduando encontra-se em processo de desenvolvimento de escrita em um domínio no qual é recém-ingresso, condição que lhe exige a incorporação de conhecimentos que o filiem a uma determinada ordem do discurso, a ordem do discurso acadêmico científico, marcada pelo alto grau de convencionalidade. 
0 aprendizado no que diz respeito a regras e normatizações, segundo Coracini (2010), faz parte dos usos orientados da linguagem, pois produzir textos depreende o alinhamento à determinada ordem do discurso: "aprender a respeitar convenções, tacitamente acordadas pelos membros de diferentes formações discursivas ou de diferentes grupos sociais". Isto é, "para entrar no jogo é preciso conhecer suas regras" (Coracini, 2010, p.21).

\section{Escrevendo na e para a academia:} o gênero relato de experiência

0 relato de experiência é um gênero estabelecido do domínio acadêmico que tem como objetivo público apresentar uma experiência didática e/ou metodológica desenvolvida consoante o auxílio de parâmetros teóricos. Nesse tipo de texto, temos a presença de um produtor que relata sua experiência como narrador-personagem (Ferreira, 2014). No entanto, dado o conjunto de convenções estabelecidas em se tratando de gêneros do domínio acadêmico-científico, a existência de um narrador-personagem não significa, necessariamente, nível irrestrito de pessoalidade já que o conhecimento partilhado pelos membros da comunidade discursiva acadêmica inclui a construção impessoal do texto (Bazerman, 1988).

Ainda conforme Bazerman, ao se observar a retórica da ciência, percebe-se que certas ferramentas e truques - e a estratégia da construção impessoal do texto, sem dúvidas, aí pode ser enquadrada - revelaram-se tão úteis que tornaram-se regularizados e até mesmo elementos obrigatórios institucionalizados de tipos particulares de comunicação científica (Bazerman, 2006, p.60).

No que tange à regularização formal, podemos descrever o gênero relato de experiência conforme modelo elaborado por Silva (2002), no qual a organização retórica do gênero pode ser esquematizada, conforme o Quadro 1. 
Quadro 1 - A organização retórica do relato de experiência didática.

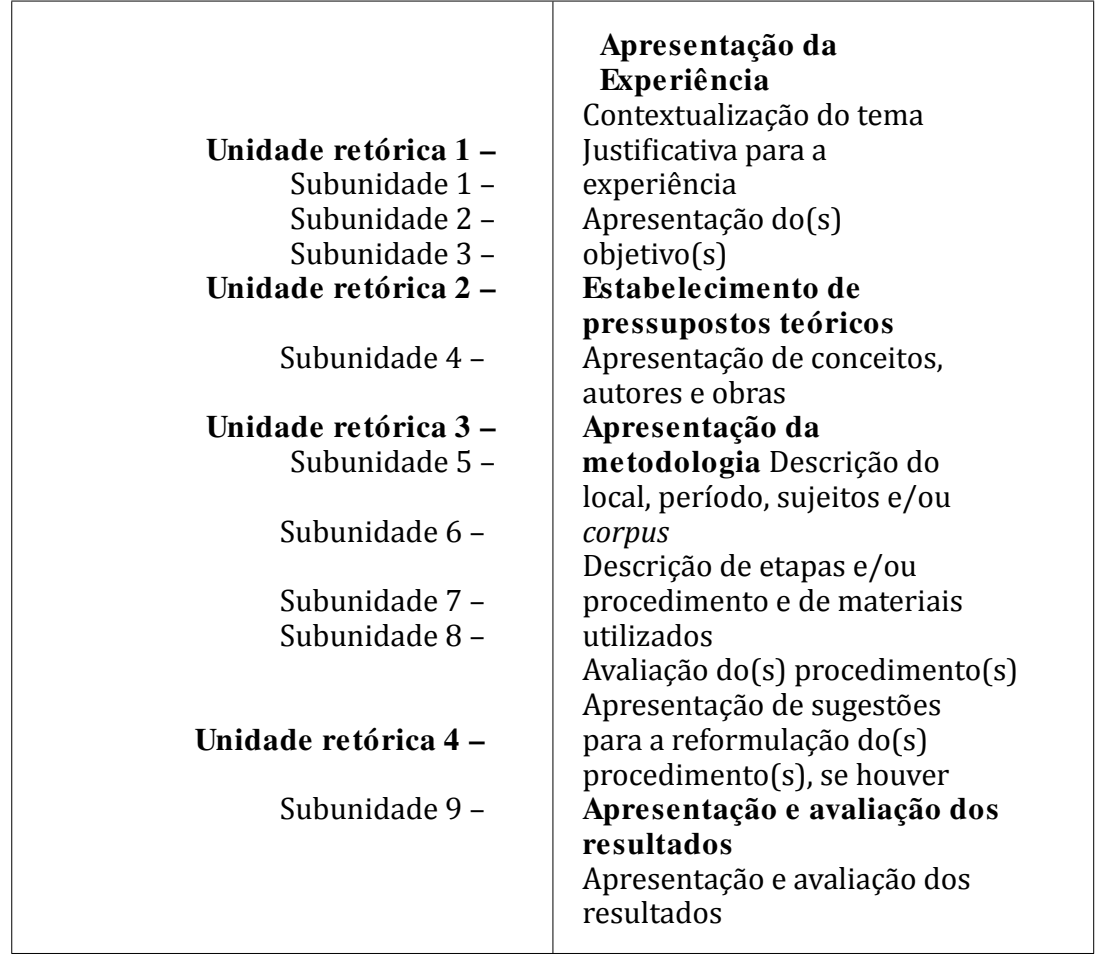

Fonte: Silva (2002, p.31).

Como podemos observar, algumas unidades retóricas costumam identificar o gênero relato de experiência, a saber: a unidade de apresentação, de fundamentação teórica, de apresentação dos fatos e, por fim, a de avaliação desses fatos. Conforme indicado em nossa introdução, este trabalho elegeu a Unidade 1 - Apresentação da experiência para empreender a análise da escrita produzida pelos sujeitos graduandos investigados.

\section{Unidade 1 - Apresentação da experiência (Introdução)}

Esta unidade retórica coaduna-se à seção de introdução e costuma apresentar informações que contextualizem acerca do tema enfocado pela experiência didática e/ou metodológica realizada, bem como aspectos referentes ao contexto geral de realização da experiência. Nesse sentido, analisaremos, inicialmente, a Produção 1, tendo em vista indicarmos a realização dessa unidade retórica e suas subunidades. 
A introdução da Produção 1, conforme veremos adiante, apresenta as três subunidades previstas por Silva (2002): subunidade 1 contextualização do tema, subunidade 2 - justificativa para a experiência e subunidade 3 - apresentação dos objetivos. Vejamo-la a seguir:

\section{Produção 1 - sujeito 1}

O ensino do seminário em aulas de língua inglesa por meio de estratégias de conversação: uma proposta de sequência didática

\section{Introdução}

Uma das atividades mais utilizadas em salas de aula, tanto em disciplinas de língua materna quanto de língua estrangeira (LE), no ensino básico e no ensino superior, é o seminário. No que diz respeito ao ensino de inglês - língua estrangeira (ILE), o seminário é uma atividade constantemente usada para se explicitar algum conteúdo específico da disciplina que relacione a língua materna com o assunto estudado, sem que haja uma contextualização da importância de seu uso, de como ele se constitui e de como pode se articular com o uso de ILE. Além disso, em certos casos, os seminários são usualmente apresentados em língua portuguesa, sem a preocupação por parte dos professores de apresentar aos seus alunos estratégias para que eles se apresentem utilizando a língua inglesa.

Assim, nos parece que o estudo, o ensino e, principalmente, o uso desse gênero se apresenta fragmentado em nossa educação, de forma que muitos professores já se acomodaram e se acostumaram a pensar que o seu ensino não diz respeito a esta disciplina, cabendo apenas aos professores de língua portuguesa ensiná-lo. E apesar de muitos já compreenderem que o ensino de ILE não pode mais ser visto de maneira estanque e formal, não conseguem (ou não querem) inserir tais atividades em seus projetos pedagógicos, mesmo sendo este um gênero de importante uso na vida de qualquer indivíduo, dentro e fora da escola.

Essas são apenas algumas das reflexões proporcionadas pelo estudo da disciplina Estudos de Oralidade e Escrita do curso de Letras da Universidade Federal de Campina Grande (UFCG), 2014, em que o seminário, dentro de seus condicionantes e suas principais características, foi levado em consideração ao se estudar gêneros articuladores do oral e da escrita. Neste estudo, que incluiu a produção e apresentação de um trabalho em torno do seminário, desenvolvemos algumas atividades relacionadas a uma sequência didática como proposta de ensino para este gênero, relacionando também outros já estudados, como o debate e a entrevista.

Logo, neste relato, pretendemos apresentar como se deu a elaboração e apresentação desse trabalho para a turma da referida disciplina, atentando especificamente para a proposta de ensino deste gênero em aulas de Inglês - língua estrangeira, explicitando a importância de seu ensino e do uso de estratégias de conversação. Tais estratégias, basicamente, dizem respeito a uma determinada prática no estudo de língua, que foram transformadas e utilizadas como estratégias de apresentação, como colaboradoras para a execução de um seminário. 
A depreensão da organização retórica construída pelo Sujeito 1 nos permite perceber o uso de diferentes estratégias, tendo em vista a tentativa de adequar-se às convenções discursivas atestadoras da condição de pertencimento à comunidade discursiva acadêmica. 0 trecho que segue indica o movimento inicial desse sujeito em sua introdução, o de apresentar a contextualização acerca do tema abordado, neste caso, o uso do gênero oral seminário em sala de aulas de Língua Inglesa.

Subunidade 1, Contextualização do tema:

A escolha pelo uso dessas estratégias se justifica pelo fato delas propiciarem uma maior contextualização daquilo que se está estudando em inglês - língua estrangeira e também a intertextualidade existente ao se relacionar as atividades de conversação, características do ensino de língua estrangeira, e o uso do seminário e/ ou de exposições orais, tanto em ILE, quanto em língua materna.

Dessa forma, organizamos este relato em: introdução, que é a presente parte; em seguida, apresentamos e explicamos os nossos procedimentos metodológicos; depois, descrevemos a apresentação da proposta de sequência didática em sala de aula à turma; e, por último, fazemos algumas reflexões acerca dessa experiência e suposições quanto à funcionalidade de nossa proposta.

Conforme podemos constatar, o Sujeito 1 realiza a subunidade 1 introduzindo um tema: o uso do seminário em sala de aula. Um ponto a se destacar nessa subunidade é a compreensão que o produtor demonstra ter acerca da necessidade de convencer o leitor quanto à relevância de seu trabalho. Percebemos isso quando ele coloca o gênero seminário como uma das atividades mais utilizadas em salas de aula e quando aponta aspectos merecedores de atenção quanto ao uso desse gênero, evidenciando a conveniência de se discutir tal uso em contexto de ensino-aprendizagem.

Tal fato, indica-nos que o Sujeito 1 já incorporou conhecimentos quanto à comunidade discursiva acadêmica, na qual procura se inserir enquanto graduando produtor, pois, conforme nos esclarece Coracini (1991), o discurso científico, típico dessa comunidade, intenciona o convencimento acerca da validade e do rigor daquilo que apresenta. No caso em análise, no qual figura um relato de experiência, justifica-se um discurso preponderantemente voltado para a validação dos apontamentos propostos, desdobrando-se no encadeamento de justificativas quanto à pertinência do tema e da problemática enfocada, o que demanda o uso de estratégias de persuasão, notadamente por meio do uso de marcas linguísticas que funcionam como operadores argumentativos (Koch, 2003). 
Constatamos a orientação argumentativa do texto pelo uso do intensificador mais em "uma das atividades mais utilizadas em sala de aula", e pelo uso do operador além disso, segundo grifo ${ }^{1}$ do excerto, que acrescenta informação ratificadora de uma mesma conclusão, a de que apesar do uso recorrente do seminário, tal uso ainda carece de reflexões. Nesse sentido, o Sujeito 1 demonstra não apenas conhecer a orientação persuasiva que costuma marcar os textos que circulam na esfera acadêmico-científica, mas também ser eficiente ao aplicar tal conhecimento à feitura de seu próprio texto.

No que tange à subunidade 2, essa se dá pela apresentação de justificativas para realização da experiência, que enfoca o ensino do gênero seminário.

Subunidade 2, Justificativa para a experiência:

Assim, nos parece que o estudo, o ensino e, principalmente, o uso desse gênero se apresenta fragmentado em nossa educação, de forma que muitos professores já se acomodaram e se acostumaram a pensar que o seu ensino não respeito a esta disciplina (inglês, LE), cabendo apenas aos professores de língua portuguesa ensiná- lo. (...) A escolha pelo uso dessas estratégias (estratégias de conversação) se justifica pelo fato delas propiciarem uma maior contextualização daquilo que se está estudando em inglês (...)

No fragmento anterior, referente à subunidade 2, justificativa para a experiência, o Sujeito 1 justifica a necessidade de se discutir a forma como o seminário tem sido concebido em aulas de língua inglesa - LE, pois, conforme ele, "parece que o estudo, o ensino e, principalmente, o uso desse gênero se apresenta fragmentado em nossa educação".

Observemos que ele inicia o parágrafo por meio de um operador cuja função é estabelecer a ideia de arremate em relação aos fatos expostos anteriormente: assim. Tais marcas linguísticas, também encontradas na subunidade 1 , indicam a atenção do produtor quanto à sequencialização lógica do texto, demonstrando seu nível de consciência linguística e textual, ainda que apresente desvios da norma linguística padrão, conforme se atesta pela não concordância do verbo apresenta, primeira linha, com o sujeito composto a que se refere.

Destaca-se também o processo de pessoalização, atestado pelo uso das formas da $1^{\mathfrak{a}}$ pessoa do plural - nos, nossa. Conforme Benveniste

\footnotetext{
${ }^{1}$ São nossos os grifos nos excertos analisados.
} 
Escrevendo na e para academia: um estudo sobre a incorporação do discurso...

(1966), a pessoalização diz respeito à explicitação do enunciador na superfície do discurso. A opção pela 1aㅡ pessoa do plural sinaliza um modo de preservação de face, à medida que pluraliza a responsabilidade pelo dito, mas também uma forma de envolvimento com o leitor, que passa a ser chamado a identificar-se com esse dito. Ainda nesse sentido, destacase o uso da estratégia de modalização, importante característica da escrita acadêmica, como se nota pelo uso que o produtor faz do modalizador parece, terceiro grifo do trecho, destinado a atenuar a responsabilidade do produtor quanto à afirmação que promove, orientando o leitor para como o discurso deve ser lido.

No que tange à construção da subunidade 3 , Apresentação do(s) objetivo(s), essa aparece a partir da exposição do objetivo do relato de experiência, por meio do qual subentende-se, consequentemente, o objetivo de realização da própria experiência:

Logo, neste relato, pretendemos apresentar como se deu a elaboração e apresentação desse trabalho (em torno do gênero seminário) para a turma, atentando especificamente para a proposta de ensino deste gênero em aulas de inglês (...)

Nesse trecho, podemos identificar a subunidade 3 por meio dos marcadores metadiscursivos ${ }^{2}$ pretendemos apresentar, que sinalizam o conteúdo informacional referente ao objetivo do trabalho. Na construção dessa subunidade, percebemos um produtor ainda em fase de desenvolvimento de escrita acadêmica, fato que se nota pelo uso do operador logo, introdutor da subunidade, o qual, mesmo carregando uma orientação argumentativa para conteúdo informacional referente à conclusão, é usado para introduzir os objetivos do trabalho. Tal fato indicia que esse produtor, embora ciente da função de conectar informações dos operadores, ainda apresenta fragilidades quanto ao conhecimento de seus conteúdos semânticos.

O Sujeito 1 ainda constrói uma subunidade não prevista pelo modelo de Silva (2002), o referente à organização interna do trabalho:

\footnotetext{
2 Marcadores metadiscusivos podem ser entendidos, consoante Motta-Roth; Hendges (2010), como pistas lexicais que caracterizam as informações presentes em diferentes segmentos do texto. Tais pistas são importantes mecanismos de identificação de diferentes movimentos do texto pelo leitor.
} 
Dessa forma organizamos este relato em: introdução, que é a presente parte; em seguida, apresentamos e explicamos os nossos procedimentos metodológicos; depois, descrevemos a apresentação da proposta de sequência didática em sala de aula à turma; e por último, fazemos algumas reflexões acerca dessa experiência e suposições à funcionalidade de nossa proposta.

Conforme se atesta pelo uso do operador dessa forma, o Sujeito 1 procura promover amarrações lógico-semânticas entre os conteúdos informacionais anteriores a essa subunidade, demonstrando a necessidade de fazer uso de operadores como modo de estabelecer relações. Embora se possa questionar o uso desse operador no contexto analisado, já que introduz o parágrafo final da unidade retórica de introdução, cujo conteúdo informacional, conforme visto, não dialoga diretamente com o conteúdo informacional exposto anteriormente, percebe-se que o produtor, mesmo desconhecendo alguns aspectos da natureza semântica dessas amarrações, está ciente de seu papel na promoção de conexões.

Destaca-se também a escolha do termo suposições, segundo grifo do trecho, utilizado para orientar o leitor quanto ao que será visto mais diante, quando a experiência realizada será analisada. Nesse sentido, a adoção do termo fragiliza o teor persuasivo típico da escrita que materializa gêneros do domínio acadêmico-científico que, conforme vimos, orienta-se pelo estabelecimento do rigor e validade de suas asserções, não coadunandose com a proposição de suposições.

Finalmente, vale salientar a construção dessa última subunidade da introdução como uma evidência do contato desse produtor com outros gêneros desse domínio, como o artigo científico, já que nesse gênero é bastante recorrente a construção dessa subunidade. Assim, provavelmente influenciado pelo contato com artigos científicos, o Produtor 1 promove a antecipação da organização informacional do trabalho para o leitor. Essa preocupação com a orientação do leitor demonstra um produtor ciente do processo de escrita como um fenômeno social de interação verbal, no qual o produtor deseja passar uma imagem de si à medida que se orienta pela imagem de seu leitor.

Com base no exposto, depreendemos algumas estratégias utilizadas pelo Sujeito 1 como meio de engajar-se nas práticas letradas da comunidade discursiva acadêmica, a saber: a) Construção da unidade retórica de apresentação em consonância com o que é altamente esperado para o gênero relato, conforme se atesta pela realização 
das três subunidades apontadas por Silva (2002). Tal fato indicia um produtor familiarizado com a estrutura retórica do gênero, o que, em consonância com Ferreira (2014), estamos tomando como pertencente à ordem do conhecimento do gênero; b) Opção por um texto orientado pelo caráter argumentativo, marcado pela recorrência de sequências que justificam a pertinência do trabalho, além do uso de operadores argumentativos, o que evidencia o conhecimento do produtor quanto ao discurso acadêmico científico, caracterizado pelo fazer persuasivo (cf. Coracini, 1991); c) Tentativa de estabelecimento de relações lógico-semânticas entre as partes do texto. Neste caso, percebemos um produtor ciente da necessidade de garantir a progressão do texto por meio do uso de diferentes marcas linguísticas, entre as quais, operadores argumentativos, demonstrando ciência quanto ao processo de textualização; d) Adoção das formas de 1aㅡ pessoa do plural (sujeito universal) como modo de garantir a preservação de face, além da anuência do leitor, estratégia que também revela conhecimento quanto à comunidade discursiva acadêmica, a qual oferece restrições quanto ao nível de pessoalidade utilizado para construção do texto; e) Construção de subunidade destinada à orientação do leitor quanto à organização informacional do trabalho, o que demonstra a construção do texto pautada pela referência à determinada audiência, evidenciando conhecimentos que passam pelo processo de textualização, pelo conhecimento do gênero e pelo conhecimento da comunidade discursiva acadêmica; f) 0 uso da estratégia de modalização, importante característica da escrita em domínio acadêmico, atestando, mais uma vez, conhecimento relativo a essa comunidade discursiva.

Vejamos, agora, como a Sujeito 2 constrói a unidade retórica 1 Apresentação da experiência, que, conforme vimos anteriormente, coaduna-se à seção destinada à introdução do trabalho: 
Produção 2 - sujeito 2 entrevista

Oralidade e Escrita: análise a respeito do trabalho com o gênero

Entendemos que a língua falada e a língua escrita são dois aspectos intimamente ligados ao homem e que entre a duas modalidades, há mais afinidade do que altercação. Essas formas de linguagens de discursos têm especificidades características, é um fato que não se pode denegar, mas é da mesma forma evidente entre elas muito em comum. Boa parte dos estudos que se refere à oralidade oral e à escrita foi feito com base em textos de conversacionais (da fala) em a checagem com textos em prosaico (da escrita). Não resta dúvida alguma que um determinado texto do colóquio espontâneo, como por exemplo: uma conversa entre amigos apresenta peculiaridades da língua falada. A mesma pode certamente representar a linguagem oral, da mesma forma um texto em prosaico, como um artigo acadêmico, apresenta características da escrita e representa, pode ser um exemplo de linguagem escrita.

Temos como objetivo principal abordar o gênero entrevista em sala de aula; assim como desenvolver nos alunos a capacidade de identificação das diferenças entre a entrevista oral e escrita; promover a transcrição de entrevistas orais e estimular o respeito entre os alunos, especialmente no que se refere ao bullying.

Conforme podemos atestar pelo excerto anterior, a introdução do relato é relativamente curta, apenas dois parágrafos, apresentando duas das subunidades apontadas por Silva (2002), a subunidade 1 Contextualização do tema e a subunidade 3 - Apresentação dos objetivos.

No entanto, antes de partirmos para a análise dessas subunidades, consideramos a pertinência de tomar a elaboração do título do trabalho como elemento atestador do nível de desenvolvimento de escrita acadêmica apresentada pelo Sujeito 2. Nesse sentido, um ponto que se destaca é o desvio da norma padrão no que tange ao uso inadequado da crase. Tal realidade indicia um produtor com um domínio ainda frágil da norma padrão da língua. Segundo Ferreira (2014), o domínio da norma linguística padrão representa uma exigência da escrita acadêmica, de modo que seu não domínio pode significar a não inserção na comunidade.

No que tange ao primeiro movimento promovido, nós o encontramos organizado em um único parágrafo, tratando-se da subunidade 1 Contextualização do tema.

Entendemos que as línguas falada e a língua escrita são dois aspectos intimamente ligados ao homem e que entre $\underline{a}$ essas duas modalidades, há mais afinidade do que altercação. Essas formas de linguagens de discursos têm 
Escrevendo na e para academia: um estudo sobre a incorporação do discurso...

especificidades características, é um fato que não se pode denegar, mas é da mesma forma evidente entre elas_muito em comum. Boa parte dos estudos que se refere à oralidade oral e a escrita foi feita com base em textos de conversacionais (da fala) em e checagem com textos em prosaico (da escrita). Não resta dúvida alguma que um determinado texto do colóquio espontâneo, como por exemplo: Uma conversa entre amigos apresenta peculiaridades $d a$ língua falada. A mesma pode certamente representar a linguagem oral, $d a$ mesma forma um texto em prosaico, como um artigo acadêmico, apresenta características da escrita e representa, exemplo de línguagem (sic) escrita.

No caso em análise, chama a atenção o fato de encontrarmos um texto confuso, prolixo, com presença de incoerências, pleonasmo, lacunas, desvios da norma linguística padrão, conforme se evidencia pelos grifos no excerto anterior. Além disso, o relato se volta para o trabalho com o gênero entrevista, no entanto, curiosamente, não encontramos nenhuma referência ao gênero nessa subunidade, pois o conteúdo informacional se volta para aspectos relativos à oralidade e à escrita, como estratégia de contextualização.

Isso não seria problemático caso o produtor, após esse conteúdo mais genérico, encaminhasse o texto para um conteúdo mais específico, ligado ao gênero entrevista, tema de seu trabalho, entretanto, não é o que acontece, ocorrendo uma quebra abrupta entre o conteúdo desse parágrafo e a subunidade 3 - Apresentação dos objetivos, construída em seguida.

Tal ruptura nos levou a suspeitar que o Sujeito 2 tivesse se utilizado da estratégia de preenchimento (Ferreira, 2014), isto é, tivesse se utilizado do plágio como modo de construir seu texto. A partir disso, realizamos uma busca na internet e, conforme suspeita, encontramos um artigo, publicado em revista da área de língua portuguesa, linguística e literatura ${ }^{3}$, do qual todo o primeiro parágrafo da introdução da Produção 2, excerto anterior, foi integralmente retirado, sem qualquer alteração.

Para Ferreira (2014), o plágio demonstra desconhecimento quanto à comunidade discursiva acadêmica, já que nela essa prática é tomada como antiética. Desse modo, fazer uso do plágio é contrariar as regras que, no interior dessa comunidade, regem o direito à autoria.

\footnotetext{
${ }^{3} \mathrm{O}$ artigo plagiado está publicado na Revista Letra Magna, Revista Eletrônica de Divulgação Científica em Língua Portuguesa, Linguística e Literatura - Ano 4 n.7 - 2o Semestre de 2007. Disponível em: <http://www.letramagna.com/ continuumtipologico.pdf>. Acesso em 10 out. 2014.
} 
Assim, o uso do plágio como estratégia de preenchimento parece demonstrar um produtor ainda desconhecedor da comunidade discursiva acadêmica, mas também indica fragilidade no que tange ao domínio do conhecimento do processo de escrita, já que, além de plagiar, o produtor não procura estabelecer relações entre o fragmento plagiado e seu próprio texto, nem tão pouco parece perceber os vários problemas do texto plagiado, isentando-se de promover nele quaisquer alterações, não se sabe se por não ter tido condições de perceber os problemas ou por falta de atenção.

Percebe-se, desse modo, que o fato de o Sujeito 2 ocupar o lugar social de graduando não o coloca, necessariamente, no lugar discursivo de membro da comunidade acadêmica, já que para isso é preciso mobilizar determinados conhecimentos, de modo a atender a convenções partilhadas pelos membros dessa comunidade.

Uma provável hipótese para explicar o comportamento do Produtor 2 é seu curto contato com as práticas que marcam essa comunidade, tendo em vista estar ele ainda em seu segundo período no curso de Letras. Ademais, depreendemos também que esse sujeito, possivelmente, encontra-se ainda muito influenciado pelas práticas de escrita que marcam o domínio escolar, no qual, por vezes, há tolerância com a atividade do tipo "Ctrl c Ctrl v".

Passemos, a partir de agora, a discutir a subunidade 3 Apresentação do(s) objetivo(s), última subunidade constitutiva da introdução da Produção 2:

Temos como objetivo principal abordar o gênero entrevista em sala de aula assim como desenvolver nos alunos a capacidade de identificação das diferenças entre a entrevista oral e escrita promover a transcrição de entrevistas orais e estimular o respeito entre os alunos, especialmente no que se refere ao Bullying.

Conforme pode-se perceber no excerto, o Sujeito 2 apresenta os objetivos de sua experiência, demonstrando, ainda que de forma incipiente, conhecimento acerca do gênero. Tal fato se atesta pelo uso de marcadores metadiscursivos - objetivo, abordar, desenvolver, promover, estimular. 0 produtor adota ainda o uso da $1^{\text {a }}$ pessoa do plural, o que demonstra alguma ciência quanto às convenções que marcam o processo 
Escrevendo na e para academia: um estudo sobre a incorporação do discurso...

de pessoalização em textos acadêmicos. No entanto, o uso dessas estratégias não é condição suficiente para garantir a unidade temática da unidade retórica de Apresentação da experiência - Introdução, de modo que o texto apresenta-se comprometido, fundamentalmente, tanto pelo desconhecimento acerca da comunidade discursiva acadêmica quanto no que tange o processo de escrita.

\section{Conclusões}

A análise das unidades retóricas de Apresentação da experiência dos relatos produzidos demonstrou a utilização de diferentes estratégias para produção do texto especializado em domínio acadêmico por graduandos do curso de Letras, indiciando, assim, produtores que se enquadram em diferentes níveis de desenvolvimento de escrita acadêmica.

O Sujeito 1 fez uso de estratégias que atestam pelo menos três conhecimentos: aqueles relacionados ao gênero, pois produziu todas as subunidades previstas por Silva (2002); conhecimentos quanto ao processo de escrita, atestados pela utilização de conectivos, marcadores metadiscursivos, argumentativos; e conhecimentos relativos à comunidade discursiva acadêmica, que se atestam pelo uso da $1^{\text {a }}$ pessoa do plural, pela tentativa de modalizar o texto, além da produção de uma escrita de caráter persuasivo. Já o Sujeito 2 demonstrou certo conhecimento do gênero, já que considerou pertinente a presença de duas das subunidades previstas por Silva (2002), no entanto, ao se utilizar da estratégia de preenchimento, por meio do plágio, esse produtor demonstra fragilidades no que tange ao processo de escrita e, principalmente, desconhecimento no que tange à comunidade discursiva acadêmica, a qual tem no plágio a violação à convenção do direito à autoria.

A partir disso, depreende-se que os sujeitos 1 e 2 encontram-se em diferentes níveis de desenvolvimento de escrita acadêmica, bem como de assunção à ordem do discurso acadêmico-científico. 0 Sujeito 1 encontra-se em nível mais avançado de desenvolvimento de escrita acadêmica quando comparado ao Sujeito 2, embora ambos pertençam ao mesmo semestre do curso. Isso porque o Sujeito 1 atende de modo mais eficiente ao conjunto de convenções que marcam a escrita em domínio acadêmico, demonstrando a ativação de conhecimentos necessários para produção do texto especializado. Tal realidade acaba por ratificar que, para além de 
conhecimentos formais, a escrita acadêmica requer que, em seu desenvolvimento, o produtor assuma o lugar discursivo de membro afinado às convenções que marcam a ordem do discurso acadêmico científico.

Para tanto, acreditamos ser necessário que um olhar mais detido seja oferecido para o processo de desenvolvimento de escrita acadêmica, principalmente por meio do reconhecimento de que cabe ao espaço acadêmico a responsabilidade de promover o ensino necessário à inserção de novos membros na comunidade discursiva acadêmica. Isso significa que é na universidade que o aluno aprende a falar e a escrever na\para a universidade. Portanto, torna-se essencial que conhecimentos necessários à produção do texto especializado, tácitos a membros experientes, possam ser mais claramente delineados e discutidos nas salas de aula de nível superior, de modo a instrumentalizar-se o aluno para o reconhecimento de marcas (linguísticas, textuais, discursivas) de inserção na comunidade acadêmica.

\section{Referências}

BARTON, D. Literacy: an Introduction to the ecology of written language. London: Blackwell, 1994.

BARTON, D.; HAMILTON, M. Literacy practices. In: BARTON, D; HAMILTON, M \& IVANIC, R. (Org.). Situated literacies: reading and writing in context. New York: Routledge, p.7-15, 2000.

BAZERMAN, C. Shaping written knowledge. Madison: The University of Wisconsin Press, 1988.

BAZERMAN, C. Gênero, agência e escrita. HOFFNAGEL, J. C; DIONISIO, A. P. (Org.). Tradução e adaptação Judith Chambliss Hoffnagel. São Paulo: Cortez, 2006.

BENVENISTE, É. Problèmes de linguistique générale I. Paris: Gallimard, 1966.

BHATIA, V. K. A análise de gêneros hoje. In: BEZERRA, B. G.; BIASE-RODRIGUES, B; CAVALCANTE, M. M. (Org.). Gêneros e sequências textuais. Recife, PE: Edupe, 2009.

CORACINI. M. J. R. F. Um fazer persuasivo: o discurso subjetivo da ciência. Campinas, SP: Pontes, 1991.

CORACINI, M. J. R. F. Discurso e escrit(ur)a de si: entre a necessidade e a (im)possibilidade de ensinar. In.: ECKERT-HOFF, B.; CORACINI, M. J. R. F. (Org.). Escrit(ur) a de si e alteridade no espaço papel-tela: alfabetização, formação de professores, línguas materna e estrangeira. Campinas, SP: Mercado das letras, 2010.

FERREIRA, Elisa Cristina Amorim. Desenvolvimento da escrita na academia: investigação longitudinal do percurso de licenciandos em Letras. Dissertação de mestrado. Universidade Federal de Campina Grande, 2014. Campina Grande - PB, $198 f$. 
Escrevendo na e para academia: um estudo sobre a incorporação do discurso...

FISCHER, A. Letramento acadêmico: uma perspectiva portuguesa. Revista Acta Scientiarum Language and Culture. Maringá. jul./dez., v.30, n.2, p.177-187, 2008.

GEE, J. P. Social linguistics and literacies: ideology in Discourses. 2ed. London/ Philadelphia: The Farmer Press, 1996.

GEE, J. P. Reading as situated language: a sociocognitive perspective. In: Journal of Adolescent \& Adult Literacy. Newark, v.8, n.44, p.714-725, 2001.

KLEMP, R. Academic literacy: making students content learners, 2004. Disponível em <http:www.greatsource.com \rehand $\backslash 6$-8\pdfs $\backslash$ Academic_Literacy.pdf>.

KOCH, I. G. V. A inter-relação pela linguagem. São Paulo: Contexto, 2003.

MILLER, Carolyn R. Genre as social action. Quarterly Journal of Speech, n.70, p.151167, 1984.

MOTTA-ROTH, D.; HENDGES, G. R. Produção textual na universidade. São Paulo: Parábola, 2010.

STREET, B. Literacy in theory and practice. Cambridge: CUP, 1984.

STREET, B. Os novos estudos sobre o letramento: histórico e perspectivas. In: MARINHO. M.; CARVALHO, G. T. (Org.). Cultura escrita e letramento. Belo Horizonte: Editora UFMG, 2010.

SILVA, Jocília Rodrigues. Relato de Experiência Didática: elementos para a descrição e ensino do gênero. 90f. Dissertação de Mestrado (Mestrado em Linguística). Universidade Federal da Paraíba - UFPB. João Pessoa, Paraíba. 2002.

SWALES, J. M. Sobre modelos de análise do discurso. In: BIASI-RODRIGUES, B.; ARAÚJO, J. G.; SOUSA, S. C. T.(Orgs.). Gêneros textuais e comunidades discursivas: um diálogo com John Swales. Belo Horizonte: Autêntica Editora, 2009.

SWALES, J. M. Genre analysis: English in academic and research settings. Cambridge: Cambridge University Press, 1990.

TARDY, C. Building genre knowledge. West Lafayette: Parlor Press, 2009. 